\title{
Synthesis, Characterization, and Crystal Structures of Molybdenum Complexes of Unsymmetrical Electron-Poor Dithiolene Ligands
}

\author{
Swagat K. Mohapatra ${ }^{\mathrm{a}, \mathrm{b}}$, Yadong Zhang, ${ }^{\mathrm{a}}$ Bhupinder Sandhu, ${ }^{\mathrm{c}}$ Marina S. Fonari, ${ }^{\mathrm{c}, \mathrm{d}}$ \\ Tatiana V. Timofeeva, ${ }^{\mathrm{c}}$ Seth R. Marder ${ }^{\mathrm{a}, *}$, Stephen Barlow ${ }^{\mathrm{a}, *}$ \\ ${ }^{a}$ School of Chemistry and Biochemistry and Center for Organic Photonics and \\ Electronics, Georgia Institute of Technology, Atlanta, GA 30332-0400 USA. \\ ${ }^{b}$ Department of Chemistry, University of Rajasthan, Jaipur 302004, India \\ ${ }^{c}$ Department of Chemistry, New Mexico Highlands University, Las Vegas, NM 87701 \\ USA \\ d Institute of Applied Physics, Academy of Sciences of Moldova, Chişinău MD-2028, \\ Moldova
}

\begin{abstract}
$\operatorname{Mo}\left(\mathrm{S}_{2} \mathrm{C}_{2}\left(\mathrm{CF}_{3}\right)_{2}\right)_{3}$, 1a, has proven a useful p-dopant in organic electronics. To develop more soluble p-dopants, $\mathrm{MoS}_{9}{ }^{2-}$ was treated with alkynes $\mathrm{CF}_{3} \mathrm{CCCO}_{2} \mathrm{Me}$ and $\mathrm{CF}_{3} \mathrm{CCCOCF}_{3}$ to give the dianions of the corresponding tris(dithiolene) complexes, $\mathbf{1 b}^{\mathbf{2}-}$ and $\mathbf{1} \mathbf{c}^{2-}$, respectively, which were then oxidized to neutral molybdenum tris[1(methoxycarbonyl)-2-(trifluoromethyl)-ethane-1,2-dithiolene], $\mathbf{1 b}$, and molybdenum tris[1-(trifluoroethanoyl)-2-(trifluoromethyl)ethane-1,2-dithiolene], $\mathbf{1 c}$, using $\mathrm{NO}^{+} \mathrm{PF}_{6}^{-}$. The crystal structures of $\left(\mathrm{NEt}_{4}{ }^{+}\right)_{2} \mathbf{1 b}^{2-},\left(\mathrm{NEt}_{4}{ }^{+}\right)_{2} \mathbf{1} \mathbf{c}^{2-}$, and neutral $\mathbf{1 c}$ have been determined. In all three cases, the metal coordination is approximately trigonal prismatic and the

* Corresponding authors.

Email addresses: stephen.barlow@chemistry.gatech.edu (S. Barlow), seth.marder@chemistry.gatech.edu (S.R. Marder).
\end{abstract}


major isomer is cis (approximately $C_{3 v}$ ). The structure of $\mathbf{1 b}^{\mathbf{2 -}}$ is distorted by a twist towards pseudo-octahedral coordination similar to that seen in structures of $\mathbf{1 a}^{\mathbf{2}}$ and $\mathrm{Mo}\left(\mathrm{S}_{2} \mathrm{C}_{2}\left(\mathrm{CO}_{2} \mathrm{Me}\right)_{2}\right)_{3}{ }^{2-}, \mathbf{1 d}^{2-}$, salts, and that of $\mathbf{1 c}$ exhibits marked folds between the planes formed by the ligand atoms and those formed by the Mo and coordinated S atoms, similar to those seen in the structure of 1a. On the other hand, the metal dithiolene core of $\mathbf{1 c}^{\mathbf{2}-}$ is essentially undistorted from $C_{3 v}$ symmetry. The oxidant strength of the neutral molecules increases in the order $\mathbf{1 d}<\mathbf{1 b}<\mathbf{1 a}<\mathbf{1 c}$, with the potentials ranging from 0.02 to $+0.39 \mathrm{~V}$ vs. the ferrocenium/ferrocene couple.

Keywords: dithiolene, electrochemistry, redox chemistry, substituent effects

\section{Introduction}

Molybdenum tris(dithiolene) complexes, $\operatorname{Mo}(\mathrm{dt})_{3}$, along with other metal tris(dithiolene)s, have a variety of interesting characteristics: the metal coordination geometries are, unusually, (approximately) trigonal prismatic; the electronic structure is challenging to describe in a simple fashion, in part due to the "non-innocence" of the dt ligands (in Green's classification scheme of covalent compounds [1] dt can be regarded as either an $\mathrm{X}_{2}$ or $\mathrm{L}_{2}$ ligand and so there is ambiguity in assigning the valence number for the metal in neutral $\mathrm{M}(\mathrm{dt})_{3}$ as 6,0 , or in between, and the electron number as 12,18 , or in between); and often multiple readily interconvertible redox states are isolable [2-12]. Moreover, $\operatorname{Mo}(\mathrm{dt})_{3}$ and other molybdenum-dithiolene derivatives have been extensively used as models [13-21] for non-nitrogenase molybdenum-containing enzymes, a universal feature of which is a cofactor containing a Mo(dt) moiety [22]. Molybdenum tris(1,2-bis(trifluoromethyl)ethane-1,2-dithiolene), Mo(tfd) 3 , 1a (Figure 1) also catalyzes 
various reactions of quadricyclane and norbornadiene [23]. 1a and related compounds containing both the tfd and other dt ligands can also reversibly bind alkenes and may be useful models for heterogeneous reactions such as the deprotection of alkenes on Raney $\mathrm{Ni}$ and hydrodesulfurization reactions [24]. The magnetic properties and conductivity of salts formed by electron transfer between various donors and neutral $\mathrm{Mo}(\mathrm{dt})_{3}$ acceptors have also been studied [25-28], while simple neutral $\mathrm{Mo}(\mathrm{dt})_{3}$ complexes have recently been found to exhibit moderate two-photon absorption in the telecommunications region of the near infrared (NIR) [29].

Molecular redox doping of organic semiconductors is useful in a variety of different device types as a means of manipulating conductivity and charge injection or collection [30]. An ideal p-dopant should be strongly oxidizing, i.e. possess a high electron affinity (EA), and cleanly accept one electron from organic semiconductor materials to form an anion that is stable with respect to chemical reactions and to diffusion within the doped film, and that does not represent a deep electrostatic trap for carriers on adjacent semiconductor molecules. At the same time, the ideal dopant itself should be stable to ambient conditions and should be compatible with both vacuum and solution processing of doped films. One of the most widely used p-dopants is the planar molecule 2,3,5,6tetrafluoro-7,7,8,8-tetracyanoquinodimethane [30], $\mathrm{F}_{4}-\mathrm{TCNQ}\left(E_{1 / 2}{ }^{0 /-}=+0.15 \mathrm{~V}\right.$ vs. $\mathrm{FeCp}_{2}{ }^{+/ 0}$ in $\mathrm{CH}_{2} \mathrm{Cl}_{2}$ [31], $\mathrm{EA}(\mathrm{s})=5.2 \mathrm{eV}$ [32]), which, however, is poorly soluble in many solvents [33], is rather volatile with a poor sticking coefficient [34, 35], is rather prone to diffusion within doped films [32, 34-37], and, due to its planarity, can form charge-transfer complexes with a number of organic semiconductors rather than undergoing an electron-transfer reaction [38-40]. Inspired in part by the work of Malcolm 
Green and co-workers in using $\mathbf{1 a}$ (Figure 1) as an acceptor in electron-transfer reactions to form molecular salts [25-27], we considered that this molecule, which was the most strongly oxidizing $\operatorname{Mo}(\mathrm{dt})_{3}$ derivative to have been isolated in its neutral state, might be a useful p-dopant. Subsequently, work carried out in collaboration with Kahn and Kippelen [31, 41-43], as well as independent work by others [44, 45], has confirmed that 1a is indeed an effective p-dopant for hole-transporting materials including triarylamine-based compounds and pentacene. Compared to $\mathrm{F}_{4}$-TCNQ, 1a has a slightly more anodic molecular reduction potential and higher solid-state EA (vide infra), has a higher molecular weight that allows for more controllable sublimation, forms an anion subsequent to doping that is less prone to diffusion within doped films [31, 41], and, due to its 3D shape, might be expected to exhibit a reduced tendency towards charge-transfer complex formation (although DFT calculations suggest that such complex formation may still occur with certain donors [46]). It has also been reported that 1a leads to higher efficiencies of generation of "free" carriers in semiconductors than the vacuumprocessible inorganic dopants $\mathrm{ReO}_{3}$ and $\mathrm{MoO}_{3}$, even though the oxides are stronger oxidants; this has been attributed to a more homogenous dispersion of the molecular dopants in the organic matrix than for the oxide dopants, which phase segregate to form crystalline nanoclusters [45]. However, although both evaporated and solution-processed semiconductor films are used in organic electronics, to date the use of 1a as a dopant has been largely restricted to evaporated films. Its solubility in common organic solvents is not particularly high, although perhaps sufficient for spin-coating using typical dopant concentrations; however, in some cases organic semiconductors heavily doped with 1a are found to precipitate from solution, precluding processing of these materials. 
Accordingly, we were interested in developing derivatives of 1a with substituents that increase both the solubility of the neutral species and of salts formed with oxidized semiconductor molecules and polymers, and that allow the oxidant properties of $\mathbf{1 a}$ to be largely retained. We have recently reported on doping of organic semiconductors and of graphene using two such compounds, $\mathbf{1 b}$ and 1c [47-50]; here we report more fully on their synthesis, spectroscopy, electrochemistry, and crystal structures.

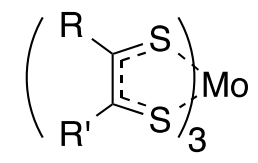

1a, $\mathrm{R}=\mathrm{R}^{\prime}=\mathrm{CF}_{3}$

1b, $\mathrm{R}=\mathrm{CF}_{3}, \mathrm{R}^{\prime}=\mathrm{CO}_{2} \mathrm{Me}$

1c, $\mathrm{R}=\mathrm{CF}_{3}, \mathrm{R}^{\prime}=\mathrm{COCF}_{3}$

1d, $\mathrm{R}=\mathrm{R}^{\prime}=\mathrm{CO}_{2} \mathrm{Me}$

Figure 1. Structures of $\operatorname{Mo}(\mathrm{dt})_{3}$ complexes discussed in this work.

\section{Experimental}

\subsection{General considerations}

Experimental details for the syntheses of $\left(\mathrm{NEt}_{4}{ }^{+}\right)_{2} \mathbf{1 b}^{\mathbf{2 -}}$ [48], $\mathbf{1 b}$ [48], $\left(\mathrm{NEt}_{4}{ }^{+}\right)_{2} \mathbf{1 c}^{\mathbf{2 -}}$ [47], and 1c [47] according to Scheme 1 have been published elsewhere. Compound 1a, used for comparison, was synthesized according to the literature [51]. UV-Vis-NIR spectra were recorded in $1 \mathrm{~cm}$ cuvettes using a CARY 5000 spectrometer. Electrochemical measurements were carried out in dry deoxygenated dichloromethane containing $0.1 \mathrm{M}$ $\mathrm{NBu}_{4}{ }^{+} \mathrm{PF}_{6}{ }^{-}$using a BAS potentiostat, a glassy carbon working electrode, a platinum wire auxillary electrode, and pseudo-reference electrode consisting of a silver wire coated with $\mathrm{AgCl}$ by anodization in aqueous $\mathrm{K}^{+} \mathrm{Cl}^{-}$solution. $\mathrm{CoCp}_{2}{ }^{+} \mathrm{PF}_{6}^{-}$was used as an internal 
standard to reference potentials to the $\mathrm{FeCp}_{2}{ }^{+/ 0}$ couple $\left(E\left[\mathrm{CoCp}_{2}{ }^{+/ 0}\right]=-1.32 \mathrm{~V}\right.$ vs.

$\left.\mathrm{FeCp}_{2}{ }^{+/ 0}\right)[52,53]$

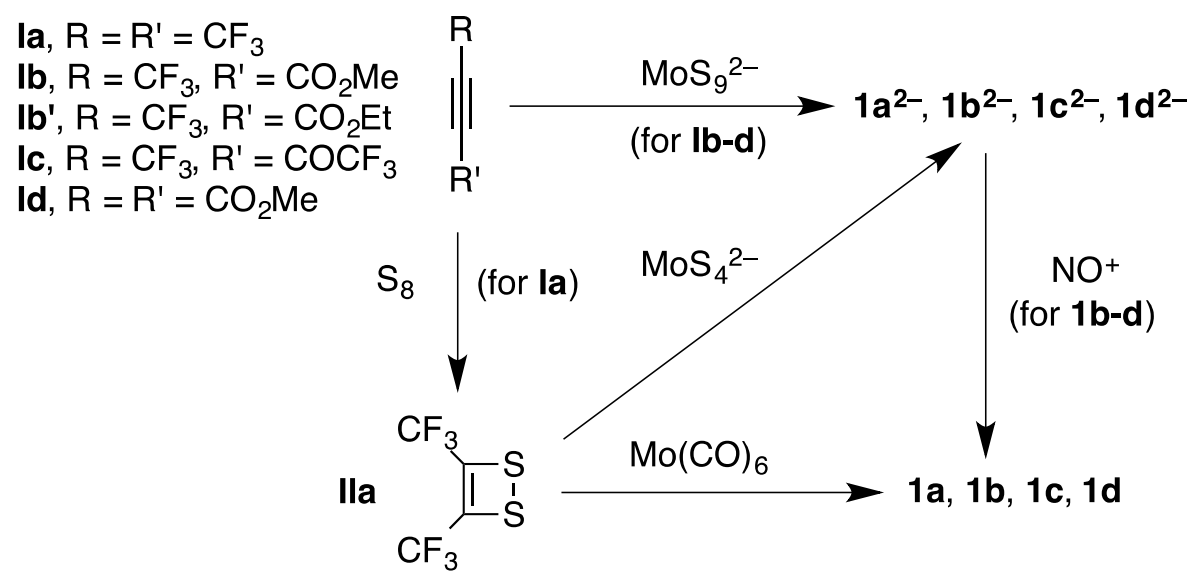

Scheme 1. Synthesis of some $\operatorname{Mo}(\mathrm{dt})_{3}$ and $\operatorname{Mo}(\mathrm{dt})_{3}{ }^{2-}$ complexes reported in the literature or discussed in the present work.

\subsection{Synthesis of $1 \mathbf{d}$}

Dimethyl but-2-ynedioate, Id $(0.77 \mathrm{~g}, 5.42 \mathrm{mmol})$ was added by syringe to a suspension of $\left(\mathrm{NEt}_{4}{ }^{+}\right)_{2} \mathrm{MoS}_{9}{ }^{2-}(1.00 \mathrm{~g}, 1.55 \mathrm{mmol})$ [54] in deoxygenated MeCN (10 mL) under nitrogen. The reaction mixture was stirred at room temperature for $1 \mathrm{~h}$, and at $50{ }^{\circ} \mathrm{C}$ for $22 \mathrm{~h}$, during which time its color turned from red-brown to dark blue. After cooling, the reaction solution was filtered through Celite and the volatiles were removed under reduced pressure. The dark blue semi-solid was dissolved in $\mathrm{CH}_{2} \mathrm{Cl}_{2}$ and then $\mathrm{MeOH}$ was added. The $\mathrm{CH}_{2} \mathrm{Cl}_{2}$ was removed under reduced pressure and the $\mathrm{MeOH}$ solution was cooled at $-80{ }^{\circ} \mathrm{C}$ overnight, affording a dark blue solid, which was collected by filtration and washed with $\mathrm{MeOH}$. This process of dissolution, $\mathrm{MeOH}$ addition, evaporation, cooling, and filtering was repeated five times to give a dark blue solid (1.10 g). The reaction was also carried out on a $10 \times$ greater scale to give $12.0 \mathrm{~g}$ of the crude salt. The 
combined crude product $(13.0 \mathrm{~g})$ was purified by Soxhlet extraction into dichloromethane to give purer $\left(\mathrm{NEt}_{4}{ }^{+}\right)_{2} \mathbf{1 d}^{2-}(8.5 \mathrm{~g})$, which, however, still contained impurities. ${ }^{1} \mathrm{H}$ NMR (400 MHz, acetonitrile- $\left.d_{3}\right): \delta 3.70\left(\mathrm{~s}, \mathrm{OCH}_{3}, 18 \mathrm{H}\right), 2.95\left(\mathrm{q}, J=7.6 \mathrm{~Hz}, 16 \mathrm{H}, \mathrm{NCH}_{2}\right), 1.08$ (t of 1:1:1 t, $\left.J_{\mathrm{HH}}=7.6 \mathrm{~Hz}, J_{\mathrm{NH}}=2.0 \mathrm{~Hz}, 24 \mathrm{H}, \mathrm{CH}_{3}\right)$. Excess $\mathrm{NO}^{+} \mathrm{PF}_{6}^{-}(0.80 \mathrm{~g}, 4.6 \mathrm{mmol})$ was added to a solution of the impure salt $(1.0 \mathrm{~g})$ in $\mathrm{CH}_{2} \mathrm{Cl}_{2}(30 \mathrm{~mL})$ and stirred at room temperature under nitrogen for $2 \mathrm{~h}$; the course of the reaction was monitored by UV-vis. absorption spectroscopy. The color of the solution turned from dark green-blue to blue and brown gas was evolved. The reaction mixture was filtered to remove insoluble impurities, the $\mathrm{CH}_{2} \mathrm{Cl}_{2}$ was removed under reduced pressure, and the resulting dark blue solid was extracted with benzene $(150 \mathrm{~mL})$. The benzene extracts were concentrated under reduced pressure (to $25 \mathrm{~mL}$ ), a portion of hexanes (100 mL) was added, and the solution was cooled at $-80{ }^{\circ} \mathrm{C}$ overnight to afford dark blue crystals $(0.3 \mathrm{~g})$. The reaction was repeated on scales of up to $7 \mathrm{~g}$ of impure $\left(\mathrm{NEt}_{4}{ }^{+}\right)_{2} \mathbf{1 d}^{2-}$. This crude product was further purified in portions: volatile impurities were sublimed at $180^{\circ} \mathrm{C}$ under $2 \times 10^{-5}$ Torr and the residue was recrystallized from $\mathrm{CH}_{2} \mathrm{Cl}_{2}$ / hexane to give pure $\mathbf{1 d}$ as a purple crystalline solid with copper-colored iridescence (total $1.1 \mathrm{~g}$ from $2.0 \mathrm{~g}$, overall yield of ca. $10 \%$ from $\left.\left(\mathrm{NEt}_{4}{ }^{+}\right)_{2} \mathrm{MoS}_{9}{ }^{2-}\right) \cdot{ }^{1} \mathrm{H} \mathrm{NMR}\left(400 \mathrm{MHz}, \mathrm{CDCl}_{3}\right): \delta .3 .96\left(\mathrm{~s}, \mathrm{OCH}_{3}\right) \cdot{ }^{13} \mathrm{C}\left\{{ }^{1} \mathrm{H}\right\}$ NMR (100 MHz, $\left.\mathrm{CDCl}_{3}\right): \delta 168.44\left(\mathrm{CO}_{2} \mathrm{Me}\right), 163.06(\mathrm{CS}), 53.76\left(\mathrm{OCH}_{3}\right)$. Anal. calcd for $\mathrm{C}_{18} \mathrm{H}_{18} \mathrm{MoO}_{12} \mathrm{~S}_{6}$ : C 30.25, H 12.54, S 26.92. Found: C 30.66, H 2.43, S 26.89.

\subsection{Crystal structure determinations}

Data for single crystals of $\left(\mathrm{NEt}_{4}{ }^{+}\right)_{2} \mathbf{1 b}^{2-}$ (dark green plate grown from methanol), $\left(\mathrm{NEt}_{4}{ }^{+}\right)_{2} \mathbf{1} \mathbf{c}^{2-}$ (dark green plate grown from isopropanol), and $\mathbf{1 c}$ (blue needle grown from hexane) were collected with a Bruker APEX-II CCD diffractometer employing Mo Ka 
radiation $(0.71073 \AA$ ) . Table 1 summarizes parameters relating to the data collection and structure refinements. Further details may be obtained in CIF format (see Appendix A). The dianion in the structure of $\left(\mathrm{NEt}_{4}{ }^{+}\right)_{2} \mathbf{1 b}^{2-}$ was modeled with disorder between $\mathrm{CF}_{3}$ and $\mathrm{CO}_{2} \mathrm{Me}$ groups in one of the dt ligands, with occupancies corresponding to a 3:1 mixture of $c i s$ (near- $C_{3 \mathrm{v}}$ ) and trans (near- $C_{\mathrm{s}}$ ) isomers (see main discussion). In another of the dt ligands of the same structure, two orientations were modeled for both the $\mathrm{CF}_{3}$ and $\mathrm{CO}_{2} \mathrm{Me}$ groups. In the structure of $\mathbf{1 c}$ two orientations were modeled for one of the $\mathrm{COCF}_{3}$ groups. 


\section{Table 1}

Crystal data and structure refinement parameters.

\begin{tabular}{|c|c|c|c|}
\hline & $\left(\mathrm{NEt}_{4}{ }^{+}\right)_{2} \mathbf{1 b}^{2-}$ & $\left(\mathrm{NEt}_{4}{ }^{+}\right)_{2} \mathbf{1 c}^{2-}$ & $1 \mathrm{c}$ \\
\hline Formula & $\mathrm{C}_{31} \mathrm{H}_{49} \mathrm{~F}_{9} \mathrm{MoN}_{2} \mathrm{O}_{6} \mathrm{~S}_{6}$ & $\mathrm{C}_{31} \mathrm{H}_{40} \mathrm{~F}_{18} \mathrm{MoN}_{2} \mathrm{O}_{3} \mathrm{~S}_{6}$ & $\mathrm{C}_{15} \mathrm{~F}_{18} \mathrm{MoO}_{3} \mathrm{~S}_{6}$ \\
\hline $\mathrm{fw} / \mathrm{g} \mathrm{mol}^{-1}$ & 1005.02 & 1118.95 & 858.45 \\
\hline crystal system & monoclinic & monoclinic & triclinic \\
\hline space group & $P 2_{1} / c$ & $P 2_{1} / c$ & $P \overline{1}$ \\
\hline$a / \AA$ & $18.7907(15)$ & $15.0261(11)$ & $8.0973(6)$ \\
\hline$b / \AA$ & $11.7438(9)$ & $13.9294(10)$ & 13.9041(11) \\
\hline$c / \AA$ & $19.7871(16)$ & 21.6441(16) & $14.5794(11)$ \\
\hline$\alpha /^{\circ}$ & 90 & 90 & $113.447(1)$ \\
\hline$\beta /^{\circ}$ & $102.937(1)$ & $106.621(1)$ & $102.336(1)$ \\
\hline$\gamma /{ }^{\circ}$ & 90 & 90 & $100.149(1)$ \\
\hline$V / \AA$ & $4255.7(6)$ & $4340.9(5)$ & $1407.26(19)$ \\
\hline$Z$ & 4 & 4 & 2 \\
\hline$\rho / \mathrm{g} \mathrm{cm}^{-3}$ & 1.569 & 1.712 & 2.026 \\
\hline$\mu(\mathrm{Mo} \mathrm{K} \alpha) / \mathrm{mm}^{-1}$ & 0.684 & 0.704 & 1.050 \\
\hline$F(000)$ & 2064 & 2256 & 828 \\
\hline$\theta$ range $/^{\circ}$ & $2.03-23.21$ & $1.76-26.00$ & $2.666-25.249$ \\
\hline no. reflections & 30173 & 40748 & 12481 \\
\hline no. indept. reflns, $R_{\text {int }}$ & $6058,0.0743$ & $8534,0.0849$ & $5094,0.0233$ \\
\hline no. reflns with $I>2 \sigma(I)$ & 4478 & 5729 & 4152 \\
\hline $\begin{array}{l}\text { data, restraints, } \\
\text { parameters }\end{array}$ & $6058,0,600$ & $5729,0,558$ & $5094,0,392$ \\
\hline $\operatorname{GOF}\left(F^{2}\right)$ & 0.986 & 1.003 & 1.010 \\
\hline$R_{1}(F)[I>2 \sigma(I)]$ & 0.0405 & 0.0607 & 0.0790 \\
\hline$w R_{2}\left(F^{2}\right)$ [all data] & 0.0977 & 0.1732 & 0.2231 \\
\hline largest peak, hole / e $\AA^{-3}$ & $0.923,-0.539$ & $1.377,-0.742$ & $1.982,-1.212$ \\
\hline
\end{tabular}




\section{Results and Discussion}

\subsection{Synthesis}

Compound 1a was first synthesized by the reaction of bis(trifluoromethyl)-1,2-dithietene, IIa, and $\mathrm{Mo}(\mathrm{CO})_{6}[2,51,55]$, while $\left(\mathrm{NEt}_{4}{ }^{+}\right)_{2} \mathbf{1 a}^{\mathbf{2}}$ has been obtained from the reaction of IIa with $\left(\mathrm{NEt}_{4}{ }^{+}\right)_{2} \mathrm{MoS}_{4}{ }^{2-}$ [56]. Compound IIa itself is obtained from the reaction of the corresponding alkyne, Ia, with refluxing sulfur [57]. We synthesized alkynes Ib [58, 59], Ib' [60], and Ic [61] according to the literature, and attempted to obtain analogous dithetenes; however, we were unable to purify the reaction products of these alkynes with boiling sulfur [62]. An alternative approach to molybdenum complexes of electron-poor dt ligands, demonstrated in the case of $\mathbf{1 d}^{\mathbf{2}}$ [63], is the reaction of the corresponding alkyne with $\mathrm{MoS}_{9}{ }^{2-}$. The alkynes Ib, Ib', and Ic all react with $\left(\mathrm{NEt}_{4}{ }^{+}\right)_{2} \mathrm{MoS}_{9}{ }^{2-}$ [54] to form blue / green materials assumed to be the corresponding $\left(\mathrm{NEt}_{4}{ }^{+}\right)_{2} \mathrm{Mo}(\mathrm{dt})_{3}{ }^{2-}$ complexes. The reaction product from Ib' was oily and not easily purified; however, $\left(\mathrm{NEt}_{4}{ }^{+}\right)_{2} \mathbf{1} \mathbf{b}^{2-}$ and $\left(\mathrm{NEt}_{4}{ }^{+}\right)_{2} \mathbf{1} \mathbf{c}^{2-}$ could be obtained pure, according to elemental analysis and to multinuclear NMR spectroscopy, after repeated extraction into dichloromethane and precipitation with methanol, or recrystallization from isopropanol, respectively. The alkynes are reasonably volatile, so the initial portion of their reaction with $\left(\mathrm{NEt}_{4}{ }^{+}\right)_{2} \mathrm{MoS}_{9}{ }^{2-}$ should be carried out at low temperature; in the case of $\mathbf{I b}$ the reaction was carried out at $0{ }^{\circ} \mathrm{C}$, and then $60^{\circ} \mathrm{C}$, in $\mathrm{MeCN}$, whereas that of Ic was carried out at $70{ }^{\circ} \mathrm{C}$, and then room temperature, in $\mathrm{CH}_{2} \mathrm{Cl}_{2}$. The purified salts of the dianions were oxidized to the corresponding neutral compounds using $\mathrm{NO}^{+} \mathrm{PF}_{6}^{-}$in $\mathrm{CH}_{2} \mathrm{Cl}_{2}(E=+1.00 \mathrm{~V}$ vs. $\left.\mathrm{FeCp}_{2}{ }^{+/ 0}[64]\right)$, which were themselves purified by extraction into hexane followed by removal of impurities by sublimation (1b) and washing with pentane, or recrystallization 
(1c). We also prepared neutral 1d in the same way; however, purification, especially of the intermediate $\left(\mathrm{NEt}_{4}{ }^{+}\right)_{2} \mathbf{1 d}^{2-}$, which seems more reluctant to solidify than the $\mathrm{PPh}_{4}{ }^{+}$salt reported in the literature [63], was more challenging, and overall yields were low. The interconversions described in this paragraph are summarized in Scheme 1.

$\mathrm{M}(\mathrm{dt})_{3}{ }^{n}$ complexes generally have approximately trigonal prismatic metal coordination ( $D_{3 h}$ symmetry for symmetric dt ligands) and so complexes of unsymmetric dt ligands can potentially exist as cis (approximately $C_{3 v}$ ) and/or trans (approximately $C_{s}$ ) isomers (Figure 2). The ${ }^{13} \mathrm{C},{ }^{19} \mathrm{~F}$, and, in the case of $\mathbf{1 b}$ and its dianion, ${ }^{1} \mathrm{H}$ NMR spectra of the present compounds indicate that all three dithiolene ligands in each complex are equivalent in solution at room temperature and, therefore, that either it is the cis isomers of both dianions and neutral species that are isolated, or that the isomers are in rapid equilibrium, the latter possibility being consistent with previous NMR studies of a range of $\mathrm{M}\left(\mathrm{S}_{2} \mathrm{C}_{2} \mathrm{ArH}\right)_{3}$ complexes $(\mathrm{M}=\mathrm{Mo}, \mathrm{W})[65,66]$.

The neutral species are more soluble in a variety of common organic solvents than $\mathbf{1 a}$, as shown in Table 2. The neutral compounds are somewhat unstable in weakly basic solvents such as acetonitrile, acetone, and THF (unless rigorously dried) [67], forming the corresponding monoanions, presumably due to reduction by traces of hydroxide, a species which is known to reduce other much less strongly oxidizing $\mathrm{Mo}(\mathrm{dt})_{3}$ complexes [68], but are stable in chlorinated and aromatic solvents such as those given in the table. 
Table 2

Approximate solubility $\left(\mathrm{mg} \mathrm{mL}^{-1}\right.$ ) of some molybdenum tris(dithiolene) complexes

\begin{tabular}{llll}
\hline Solvent & $\mathbf{1 a}$ & $\mathbf{1 b}$ & $\mathbf{1 c}$ \\
\hline Chloroform & $4-5$ & 100 & 30 \\
Chlorobenzene & 3 & 50 & 25 \\
Toluene & $2.5-3.0$ & 40 & 20 \\
\hline
\end{tabular}

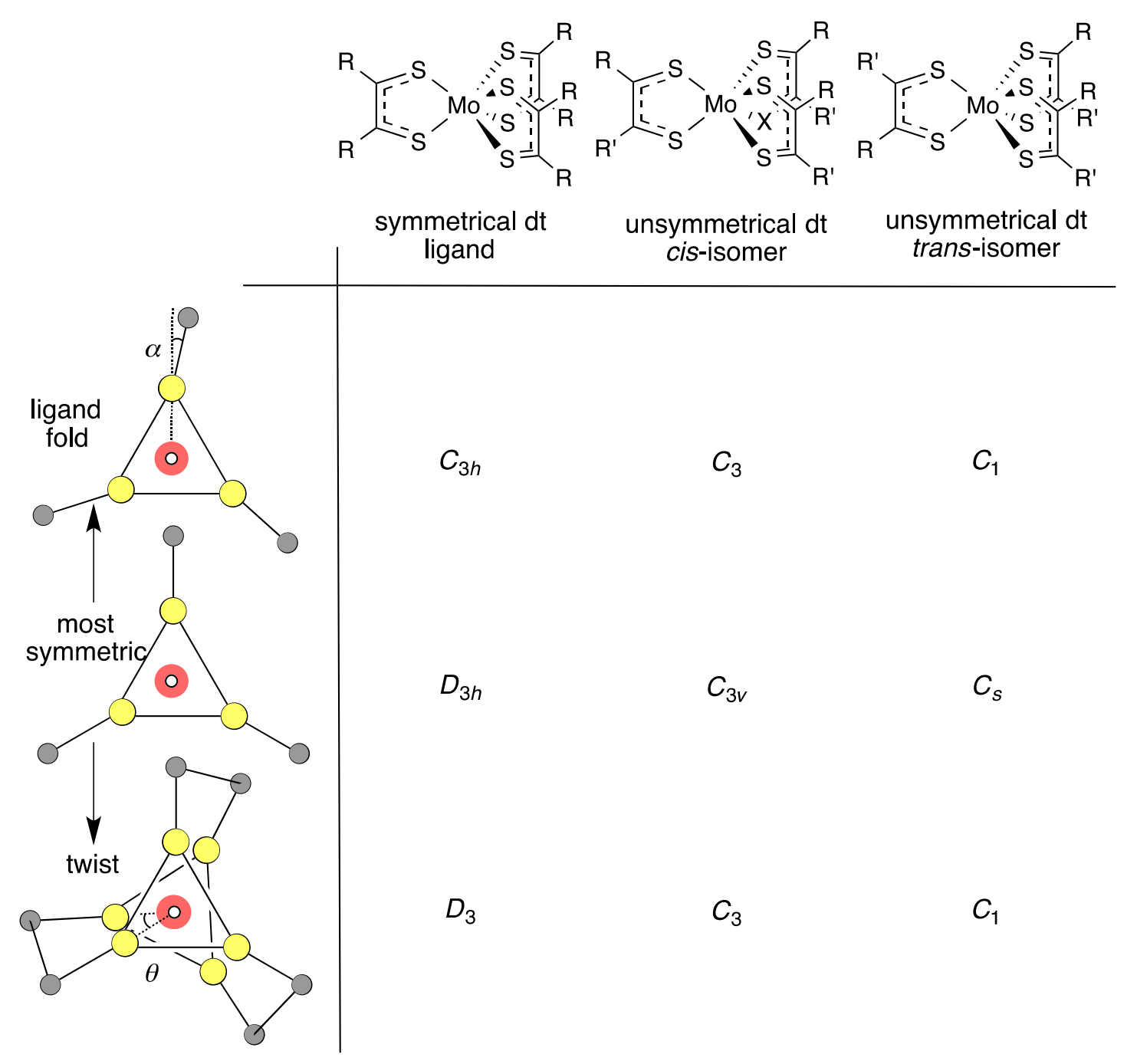

Figure 2. The chemical structures show $\operatorname{Mo}(\mathrm{dt})_{3}$ complexes of symmetrical and 
unsymmetrical dt ligands (two isomers). The schematic diagrams on the left show a Mo(dt) ${ }_{3}$ complex (substituents omitted) viewed along the axis formed by the centroids of the two triangular faces of the trigonal prism of $S$ atoms (and the central metal atom) in the case of the most symmetric structure possible and the most common structural distortions, defining the angles $\alpha$ and $\theta$ used in the discussion of crystal structures. The point groups obtained for each combination of chemical structure and structural distortion are shown.

\subsection{Crystal structures}

X-ray crystal structures have been determined for $\left(\mathrm{NEt}_{4}{ }^{+}\right)_{2} \mathbf{1 b}^{2-},\left(\mathrm{NEt}_{4}{ }^{+}\right)_{2} \mathbf{1 c}^{2-}$, and $\mathbf{1 c .} \mathrm{A}$ view of the molecular structure of each is shown in Figure 3. As is typical for $\mathrm{M}(\mathrm{dt})_{3}{ }^{n}$ complexes $[10,12]$, the sulfur atoms are arranged in a roughly trigonal prismatic arrangement around the metal in each complex. For $\left(\mathrm{NEt}_{4}{ }^{+}\right)_{2} \mathbf{1 c}^{2-}$ and $\mathbf{1 c}$ the crystal structures reveal the presence of only the cis isomers. In the case of $\left(\mathrm{NEt}_{4}{ }^{+}\right)_{2} \mathbf{1 b}^{2-}$, however, disorder was modeled as a 3:1 mixture of cis and trans isomers, further suggesting that the NMR data reflect an interconverting mixture of isomers. To the best of our knowledge, the only previous crystallographically characterized example of a $\operatorname{Mo}(\mathrm{dt})_{3}$ complexes of an unsymmetrical dithiolene ligand is that of molybdenum tris $(3,5-$ di-tert-butylbenzene-1,2-dithiolate), in which the electronic asymmetry between the two binding sites is presumably considerably less than in the present series of compounds, and for which the trans isomer is found [7]. The trans isomer is expected to be favored entropically and indeed was found to be the dominant species in previous variabletemperature NMR studies of complexes of unsymmetrical dithiolenes for which there was little differences in enthalpy between the two isomers [65]; the finding of 
predominately cis isomers in the present work may reflect either enthalpic preferences arising from a stronger inequivalence between the two binding sites and/or crystalpacking effects.
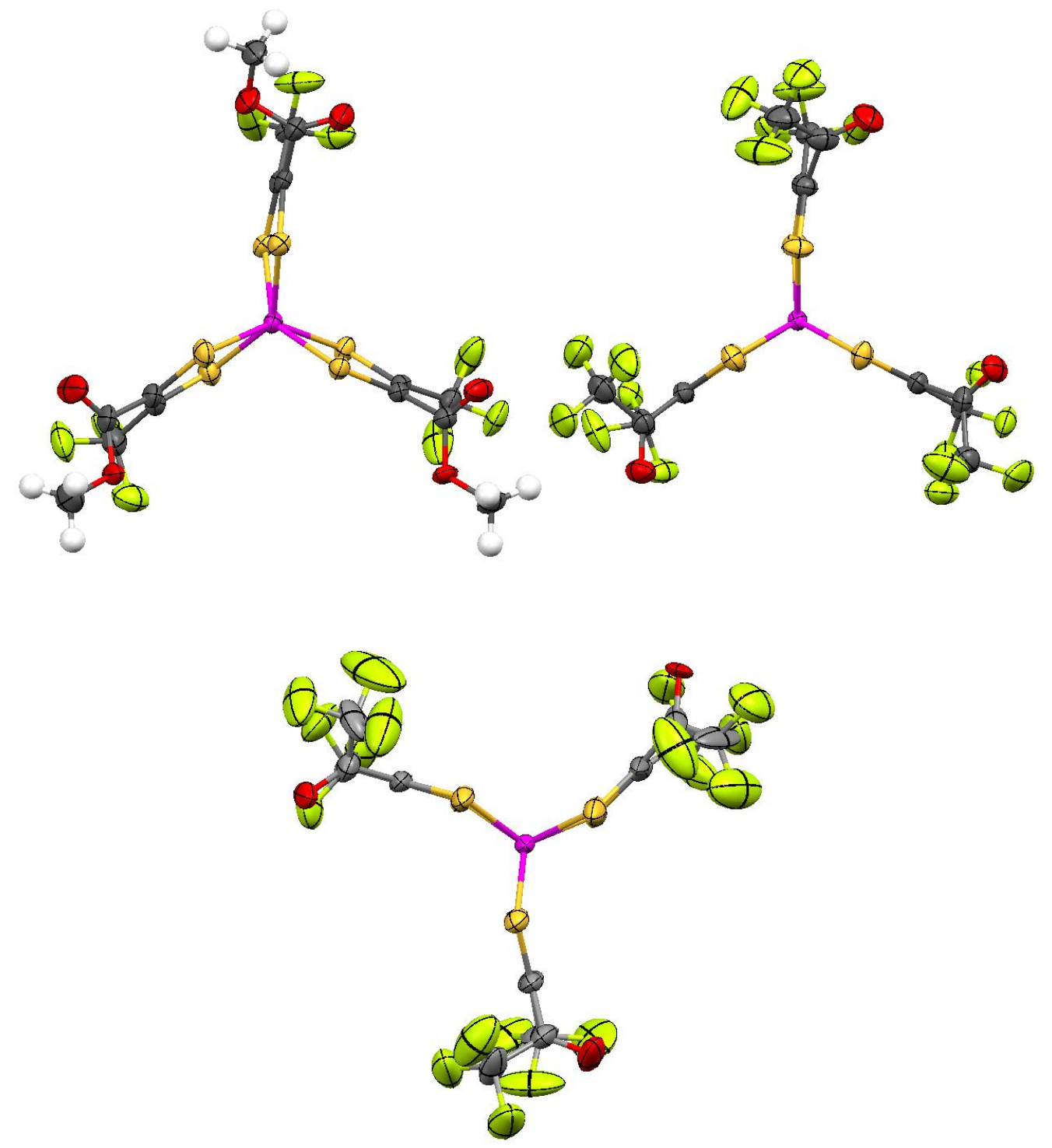

Figure 3. Molecular structures of the $\operatorname{Mo}\left(\mathrm{dt}_{3}\right)^{n}$ species in the crystal structures of $\left(\mathrm{NEt}_{4}{ }^{+}\right)_{2} \mathbf{1 b}^{2-}$ (top left), $\left(\mathrm{NEt}_{4}{ }^{+}\right)_{2} \mathbf{1 c}^{2-}$ (top right), and $\mathbf{1 c}$ (bottom), viewed along the axes formed by the Mo atom and the centroids of the two triangular faces of the trigonal prism to emphasize the distortions from ideal $C_{3 v}$ symmetry. Only the major isomer of $\left(\mathrm{NEt}_{4}{ }^{+}\right)_{2} \mathbf{1 b}^{2-}$ and the principal conformers of the substituents are shown. 
Table 3 compares key geometric features for the three complexes to those found for the most closely related $\operatorname{Mo}(\mathrm{dt})_{3}{ }^{n}$ structures in the literature, those of $1 \mathbf{a}$ and $\mathbf{1 d}$ in various oxidation states $[26,56,63]$. More extensive tabulations of $\mathrm{Mo}(\mathrm{dt})_{3}{ }^{n}$ geometric parameters may be found in the literature $[9,10,12]$. The extent to which the coordination geometry in each structure is distorted from approximate $D_{3 h}\left(\mathbf{1 a}^{n}\right.$ and $\left.\mathbf{1 d}^{n}\right)$ or $C_{3 v}$ (major isomer of $\mathbf{1} \mathbf{b}^{n}$ and $\mathbf{1} \mathbf{c}^{n}$ ) geometry has been gauged in the literature using two angles, $\theta$ and $\alpha[10,12]$. The angle $\theta$ quantifies the extent to which the coordination is distorted from $D_{3 h}$ or $C_{3 v}$ towards pseudo-octahedral geometry ( $D_{3}$ or $C_{3}$ respectively) through a twist of one triangular face relative to the other; here it is defined as the average over all three ligands of the torsion angle formed by the sulfur atom on the top triangular face, the centroid of that face, the centroid of the other face, and the sulfur atom in the same ligand on the other face. The angle $\alpha$ is the angle between the plane formed by the S-C-C-S atoms of each ligand and the corresponding S-Mo-S plane; the values given here are averaged over all three ligands taking the sign of the angle into account.

The bond lengths are generally similar to those of other $\operatorname{Mo}\left(\mathrm{S}_{2} \mathrm{C}_{2} \mathrm{R}_{2}\right)_{3}$ derivatives in the same oxidation state. The lengthening of the $\mathrm{Mo}-\mathrm{S}$ and $\mathrm{C}-\mathrm{S}$ bonds and the shortening of the $\mathrm{C}(\mathrm{S})-\mathrm{C}(\mathrm{S})$ bonds seen between $\mathbf{1 c}$ and $\mathbf{1} \mathbf{c}^{2-}$ are similar to what is seen between 1a, $1 \mathbf{a}^{-}$, and $\mathbf{1 a}^{2-}[26,56]$, and in a series of $\operatorname{Mo}\left(\mathrm{S}_{2} \mathrm{C}_{2} \mathrm{Me}_{2}\right)_{3}{ }^{n}\{n=0,-1,-2\}$ structures $[14,15] . \mathbf{1 b}^{2-}$ is also characterized by a significant twist from an ideal trigonal prismatic geometry, intermediate between the values seen for $\mathbf{1 a}^{2-}[26,56]$ and $\mathbf{1 d}^{2-}[63]$, while the structure of $1 \mathbf{c}^{2-}$ exhibits essentially no twist. Although most $\operatorname{Mo}(\mathrm{dt})_{3}{ }^{2-}$ structures determined to date exhibit significant twists $\left(\theta=10-35^{\circ}\right)[10,12]$, there are precedents 
for untwisted structures; for example, dianion structures for $\mathrm{dt}=\mathrm{S}_{2} \mathrm{C}_{6} \mathrm{H}_{2} \mathrm{Cl}_{2}$ and $\mathrm{S}_{2} \mathrm{C}_{2} \mathrm{Me}_{2}$ are characterized by $\theta<3^{\circ}[69,70]$. The lack of common electronic features among the more-or-less untwisted dianions suggests that this structural parameter can be influenced by crystal packing effects; indeed, $\mathrm{Mo}\left(\mathrm{S}_{2} \mathrm{C}_{2}(\mathrm{CN})_{2}\right)_{3}{ }^{2-}$ is much less twisted from $D_{3 h}$ symmetry in its $\left[\mathrm{Ag}_{2}(\mathrm{MeCN})_{2}\left(\left(\mathrm{Ph}_{2} \mathrm{P}\right)_{2} \mathrm{NH}\right)\right]^{2+}$ salt [71] than in its $\mathrm{EPh}_{3}{ }^{+}\{\mathrm{E}=\mathrm{P}$, As $\}$ salts $[9,72]$, while $\mathrm{W}\left(\mathrm{S}_{2} \mathrm{C}_{6} \mathrm{H}_{2} \mathrm{Cl}_{2}\right)_{3}{ }^{2-}$ is much less twisted with $\mathrm{NEt}_{4}{ }^{+}$as a counterion than with $\mathrm{PPh}_{3}^{+}[69]$.

In contrast to what is seen in the structures of $\mathrm{Mo}(\mathrm{dt})_{3}{ }^{2-}$ salts, neutral $\mathrm{Mo}(\mathrm{dt})_{3}$ species are typically essentially untwisted, but their ligands are significantly folded along the $\mathrm{S}-\mathrm{S}$

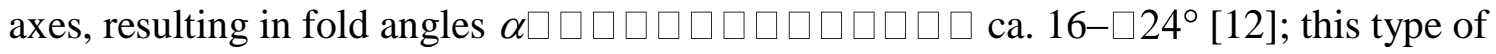
distortion has been rationalized as allowing mixing between the otherwise orthogonal HOMO and LUMO [73]. Neutral $\mathbf{1 c}$ is no exception to this general pattern: the value of $\alpha$ is larger than for 1a [56] or any other hitherto reported neutral $\mathrm{Mo}(\mathrm{dt})_{3}$ complexes with only "olefinic" dithiolene $\left(\mathrm{dt}=\mathrm{S}_{2} \mathrm{C}_{2} \mathrm{R}_{2}\right)$ ligands $(\mathrm{R}=\mathrm{H}, \mathrm{Me}, \mathrm{Et}, \mathrm{Ph})[3,9,14,74]$, but smaller than those reported to date for neutral $\mathrm{Mo}(\mathrm{dt})_{3}$ complexes of "aromatic" ligands $\left(\mathrm{dt}=\mathrm{S}_{2} \mathrm{C}_{6} \mathrm{H}_{4}\right.$ and $\left.\mathrm{S}_{2} \mathrm{C}_{6} \mathrm{H}_{2}{ }^{\mathrm{t}} \mathrm{Bu}_{2}\right)[7,75]$. 


\section{Table 3}

Comparison of structural parameters $\left(\AA,^{\circ}\right)$ for some molybdenum tris(dithiolene)s

\begin{tabular}{|c|c|c|c|c|c|c|}
\hline \multirow[t]{2}{*}{ Compound } & \multicolumn{3}{|c|}{ bond lengths (range and average) / $\AA$} & \multirow[t]{2}{*}{$\theta /{ }^{\circ a}$} & \multirow[t]{2}{*}{$\alpha /^{\circ b}$} & \multirow[t]{2}{*}{ Ref. } \\
\hline & $\overline{\mathrm{Mo}-\mathrm{S}}$ & $\mathrm{S}-\mathrm{C}$ & $C(S)-C(S)$ & & & \\
\hline \multicolumn{7}{|l|}{ Neutral } \\
\hline $1 \mathbf{a}$ & $2.355(4)^{c}$ & $1.695(14)^{c}$ & $1.37(3)^{c}$ & 0 & 17.7 & {$[56]$} \\
\hline \multirow[t]{2}{*}{ 1c } & $2.351(3)-2.363(3)$ & $1.664(16)-1.745(17)$ & $1.34(2)-1.354(13)$ & 0.4 & 20.4 & this work \\
\hline & 2.359 & 1.706 & 1.35 & & & \\
\hline \multicolumn{7}{|l|}{ monoanions } \\
\hline \multirow[t]{2}{*}{$\mathrm{FeCp}_{2}{ }_{2}^{+} \mathbf{1 a}^{-}$} & $2.361(3)-2.369(3)$ & $1.71(1)-1.718(8)$ & $1.36(2)-1.37(1)$ & 0 & 0.2 & {$[26]$} \\
\hline & 2.366 & 1.715 & 1.37 & & & \\
\hline \multicolumn{7}{|l|}{ dianions } \\
\hline \multirow[t]{2}{*}{$\left(\mathrm{NEt}_{4}{ }^{+}\right)_{2} \mathbf{1 a}^{2-}$} & $2.3695(12)-2.3806(13)$ & $1.734(5)-1.741(5)$ & $1.334(7)-1.339(8)$ & 15.8 & 0.0 & [56] \\
\hline & 2.375 & 1.738 & 1.336 & & & \\
\hline \multirow[t]{2}{*}{$\left(\mathrm{FeCp}_{2}{ }^{+}\right)_{2} \mathbf{1 a}^{2-}$} & $2.361(2)-2.391(2)$ & $1.727(7)-1.754(6)$ & $1.35(1)-1.358(8)$ & 15.9 & 5.0 & [26] \\
\hline & 2.379 & 1.739 & 1.35 & & & \\
\hline
\end{tabular}




\begin{tabular}{|c|c|c|c|c|c|c|}
\hline \multirow[t]{2}{*}{$\left(\mathrm{NEt}_{4}{ }^{+}\right)_{2} \mathbf{1 b}^{2-}$} & $2.3800(12)-2.3977(12)$ & $1.742(4)-1.753(4)$ & $1.324(6)-1.332(6)$ & 12.9 & 1.6 & this work \\
\hline & 2.388 & 1.747 & 1.329 & & & \\
\hline \multirow[t]{2}{*}{$\left(\mathrm{NEt}_{4}^{+}\right)_{2} \mathbf{1 c}^{2-}$} & $2.3720(14)-2.3972(14)$ & $1.731(5)-1.746(5)$ & $1.339(8)-1.351(8)$ & 1.5 & 0.8 & this work \\
\hline & 2.386 & 1.739 & 1.345 & & & \\
\hline \multirow[t]{2}{*}{$\left(\mathrm{PPh}_{4}{ }^{+}\right)_{2} \mathbf{1 d}^{\mathbf{2 -}}$.DMF. $\mathrm{C}_{6} \mathrm{H}_{6}$} & $2.385(6)-2.399(5)$ & $1.72(2)-1.76(2)$ & $1.28(2)-1.38(2)$ & 10.6 & 4.3 & [63] \\
\hline & 2.393 & 1.74 & 1.34 & & & \\
\hline
\end{tabular}

${ }^{a} \theta$ is the average intraligand $\mathrm{S} 1-\mathrm{cen} 1-\mathrm{cen} 2-\mathrm{S} 2$ torsion angle, where cen1 and cen2 are the centroids of the triangular faces of the trigonal prisms. ${ }^{b} \alpha$ is the average fold angle of the ligand, defined as the angle between the S1,S2,Mo plane and the S1,S2,C1,C2 plane. ${ }^{c}$ Molecule has crystallographic $C_{3 h}$ symmetry; i.e. all $6 \mathrm{Mo}-\mathrm{S}$ bond lengths are equal, all $6 \mathrm{~S}-\mathrm{C}$ bond lengths are equal, and all $3 \mathrm{C}(\mathrm{S})-\mathrm{C}(\mathrm{S})$ bonds are equal and so no ranges or averages are given. 


\subsection{Electrochemistry}

As one might expect from their successful synthesis from the corresponding dianions, both cyclic voltammetry and differential pulse voltammetry indicate that $\mathbf{1 b}$ and $\mathbf{1 c}$ exhibit two reversible one-electron reductions, as do 1a and 1d. Figure 4 compares reductive differential pulse voltammograms for the four compounds, while the corresponding potentials are given in Table 4 . The solution oxidant strength, $E^{0 /-}$, of the neutral compounds examined spans a range of ca. $0.4 \mathrm{~V}$. Although the $\left[\mathrm{Mo}\left(\mathrm{S}_{2} \mathrm{C}_{2}(\mathrm{CN})_{2}\right)_{3}\right]^{0 /-}$ couple is even more oxidizing $[9,76], \mathbf{1} \mathrm{c}$ is the most strongly oxidizing $\mathrm{Mo}(\mathrm{dt})_{3}$ complex to have been isolated in the neutral state. Values of the solidstate EA [77, 78], which are more relevant to determining the feasibility of electron transfer to the dopant from a semiconductor film, have previously been measured for 1a and $\mathbf{1 b}$ with inverse photoelectron spectroscopy and are also given in the table [31, 48]; these values indicate a much larger difference in oxidant strengths in the solid state than in solution, illustrating the pitfalls of estimating EA(s) from electrochemical data [79].

The ordering of the potentials correlates with the $\sigma$-electron-withdrawing properties of the substituents, as quantified, for example, by the average value of the inductive / field parameter $F$ [80], but not with their $\pi$-electron-withdrawing properties, as quantified, for example, by the parameter $R^{-}$[80], based on which one would expect the ester derivatives to be stronger oxidants than 1a. Indeed the crystal structures described above for $\mathbf{1 b}-\mathbf{1 d}$ in various oxidation states suggest generally ineffective overlap of the local $\mathrm{C}=\mathrm{O} \pi^{*}$ orbitals and the $\pi$ or $\pi^{*}$ orbitals of the dithiolene ligands to which they are attached; angles between the $\mathrm{S}-\mathrm{C}-\mathrm{C}-\mathrm{S}$ and $\mathrm{O}=\mathrm{C}-\mathrm{X}\left(\mathrm{X}=\mathrm{O}(\mathrm{Me})\right.$ or $\left.\mathrm{C}\left(\mathrm{F}_{3}\right)\right)$ planes for $\mathbf{1 c}, \mathbf{1} \mathbf{b}^{\mathbf{2}}, \mathbf{1} \mathbf{c}^{\mathbf{2}}$ fall in 
the ranges $51-89^{\circ}, 65-82^{\circ}$, and $67-81^{\circ}$, respectively, although values for $\mathbf{1 d}^{\mathbf{2}}$ range from $12-73^{\circ}[63]$. Perhaps surprisingly, a better correlation of the redox potentials is obtained with $R^{+}$, which gauges the ability of a substituent to stabilize a positive charge by resonance, than with $F$ (Figure 4, right), apparently suggesting that any $\pi$-effects are more likely to involve stabilization of a (partial) positive charge in the oxidized species than that of the negative charge of the reduced species [81]. This correlation is consistent with previous studies have found that various properties of $\mathrm{W}(\mathrm{dt})_{3}$ compounds with $p$ substituted aryl substituents correlate at least as well with ${\sigma_{\mathrm{p}}}^{+}$values for the substituents as with those of $\sigma_{\mathrm{p}}$ [66]. On the other hand, the reliability of values of $R^{+}$for essentially $\pi$-accepting substituents, such as those used in the present work, has been questioned [80], so perhaps the apparently good correlation with reduction potentials is an artifact of unreliable values. Solvation effects that significantly differ from those in the appropriate reference reactions used to derive values of the substituent parameters may also play a role in the observed correlations. 

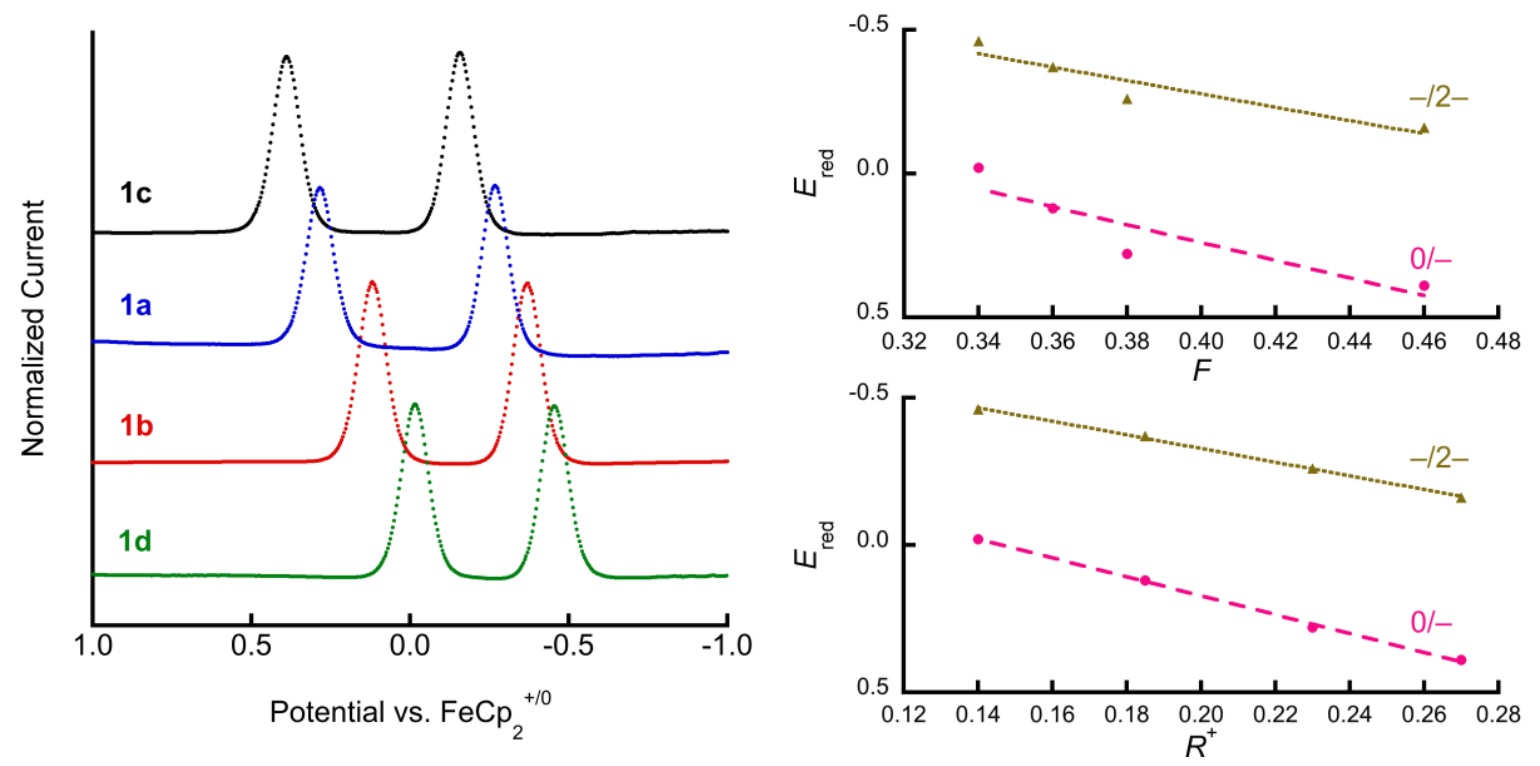

Figure 4. Left: reductive differential pulse voltammograms for $\operatorname{Mo}(\mathrm{dt})_{3}$ compounds in $\mathrm{CH}_{2} \mathrm{Cl}_{2} / 0.1 \mathrm{M} \mathrm{NBu}_{4}{ }^{+} \mathrm{PF}_{6}{ }^{-}$. The peak currents have been normalized between voltammograms and the voltammograms vertically displaced from one another for clarity. Right: plots of redox potentials plotted vs. two different substituent parameters (values for $\mathrm{CF}_{3}, \mathrm{CO}_{2} \mathrm{R}$, and $\mathrm{COCF}_{3}$ taken from Table $\mathrm{V}$ of ref. [80]; for $\mathbf{1 b}$ and $\mathbf{1 c}$ values for the two different substituents were averaged) with best-fit lines. 


\section{Table 4}

Electrochemical and optical data for $\mathrm{Mo}(\mathrm{dt})_{3}$ compounds.

\begin{tabular}{|c|c|c|c|c|c|c|}
\hline & \multicolumn{2}{|c|}{${E_{\text {red }}}^{a} / \mathrm{V}$ vs. $\mathrm{FeCp}_{2}^{+/ 0}$} & \multirow{2}{*}{$\begin{array}{c}\mathrm{EA}(\mathrm{s}) / \\
\mathrm{eV}^{b}\end{array}$} & \multicolumn{3}{|c|}{$\lambda_{\max }\left(\varepsilon_{\max }\right)^{c} / \mathrm{nm}\left(10^{3} \mathrm{M}^{-1} \mathrm{~cm}^{-1}\right)$} \\
\hline & $\operatorname{Mo}(\mathrm{dt})_{3}{ }^{0 /-}$ & $\operatorname{Mo}(\mathrm{dt})_{3}^{-/ 2-}$ & & $\mathrm{Mo}(\mathrm{dt})_{3}$ & $\mathrm{Mo}(\mathrm{dt})_{3}^{-}$ & $\operatorname{Mo}(\mathrm{dt})_{3}{ }^{2-}$ \\
\hline $1 \mathbf{a}$ & +0.28 & -0.26 & 5.6 & $386(8.5), 583(11)$ & $d e$ & $d f$ \\
\hline $\mathbf{1 b}$ & +0.12 & -0.37 & 5.0 & $397(9.9), 594(13)$ & $377(4.0), 488(1.8), 664(3.6), 942(0.4)$ & $644(5.0)$ \\
\hline 1c & +0.39 & -0.16 & $d$ & $399(10), 596(14)$ & $374(4.0), 491(1.8), 669$ (3.6). 957 (0.5) & $479(4.0), 663(5.0)$ \\
\hline 1d & -0.02 & -0.46 & $d$ & $d$ & $d$ & $d g$ \\
\hline
\end{tabular}

${ }^{a}$ Peak reduction potentials from DPV in $\mathrm{CH}_{2} \mathrm{Cl}_{2} / 0.1 \mathrm{NBu}_{4}{ }^{+} \mathrm{PF}_{6}{ }^{-} ; E_{1 / 2}$ values from cyclic voltammetry are almost identical. ${ }^{b}$

Adiabatic electron affinity for neat films determined using inverse photoelectron spectroscopy and taken from refs. [31] and [48] for 1a and $\mathbf{1 b}$, respectively. ${ }^{c}$ In $\mathrm{CH}_{2} \mathrm{Cl}_{2}$; counterions for ionic species $\mathrm{NEt}_{4}{ }_{4}$; monoanions generated by comproportionation of neutral and dianionic species. ${ }^{d}$ Not measured. ${ }^{e}$ See ref. [31]. ${ }^{f} \lambda_{\max }=328,622 \mathrm{~nm}$ in MeCN; see ref. [56]. ${ }^{g} \lambda_{\max }\left(\varepsilon_{\max }\right)=356(11.5), 650(5.8) \mathrm{nm}$ $\left(10^{3} \mathrm{M}^{-1} \mathrm{~cm}^{-1}\right)$ in $\mathrm{MeCN}$; see ref. [63]. 


\subsection{Absorption spectra}

The electronic absorption spectra of families of $\operatorname{Mo}(\mathrm{dt})_{3}{ }^{n}\{\mathrm{n}=0,-1,-2\}$ species (see ref. [12] for a table of literature electronic spectroscopic data) show two main patterns of behavior. Firstly, for the "olefinic" $\mathrm{S}_{2} \mathrm{C}_{2} \mathrm{H}_{2}$ ligand, both neutral and dianionic species exhibit two prominent transitions at ca. 400 and $600 \mathrm{~nm}$, the high- and low-energy maxima of the dianion being respectively hypso- and bathochromically shifted relative to those of the neutral compound and both being less strongly absorbing, while the main features of the monoanion spectrum are similar to those in the dianion with the addition of a weak low-energy feature at ca. $1000 \mathrm{~nm}[5,9]$. Similar spectra are seen for $\operatorname{Mo}\left(\mathrm{S}_{2} \mathrm{C}_{2} \mathrm{ArH}\right)_{3}{ }^{n}\{\mathrm{Ar}=\mathrm{Ph}, n=0,-1,-2 ; \mathrm{Ar}=2$-naphthyl, $n=0\}[9,29]$, but the phenyl substituents lead to consistently lower energy transitions in each oxidation state. The second class consists of complexes of "aromatic" dithiolenes (i.e., $\mathrm{S}_{2} \mathrm{C}_{6} \mathrm{H}_{4-x} \mathrm{R}_{x}$, ligands that can be described as $o$-arenedithiolates or dithio-o-quinones in their dianionic or neutral forms, respectively); the neutral and dianionic complexes also exhibit two principal transitions, but the low-energy dianion peak is blue-shifted relative to the main low-energy neutral peak and both peaks have much higher absorptivity than those for $\operatorname{Mo}\left(\mathrm{S}_{2} \mathrm{C}_{2} \mathrm{H}_{2}\right)_{3}{ }^{n}$. Moreover, the monoanion spectra show multiple absorption peaks and much less closely resemble those of the corresponding dianions than is the case for the olefinic species [7, 9]. The qualitative differences in monoanion spectra between these alkyl-substituted olefinic and aromatic classes of compounds are paralleled by differences in structure, with approximately $D_{3 h}\left(\theta \sim 0\right.$ for $\left.\mathrm{dt}=\mathrm{S}_{2} \mathrm{C}_{2} \mathrm{Me}_{2}[14]\right)$ and $D_{3}\left(\theta>30^{\circ}\right.$ for dt $=\mathrm{S}_{2} \mathrm{C}_{6} \mathrm{H}_{4-x} \mathrm{R}_{x}[7,68,82] ; 14.6^{\circ}$ for $\mathrm{S}_{2} \mathrm{C}_{8} \mathrm{H}_{4} \mathrm{~N}_{2}$ [83]) geometries, respectively, being found in crystal structures, in electron-spin resonance (ESR) spectra [9], and in sulfur K-edge 
X-ray absorption spectroscopy; DFT calculations suggest these differences are related to a difference in the ordering of the frontier orbitals, resulting in primarily ligand- and metal-based semi-occupied molecular orbitals (SOMOs) for $\mathrm{Mo}(\mathrm{dt})_{3}{ }^{-}$complexes with olefinic and aromatic ligands, respectively $[8,9]$. The $\operatorname{Mo}\left(\mathrm{S}_{2} \mathrm{C}_{2} \mathrm{Ph}_{2}\right)_{3}{ }^{n}$ series shows somewhat intermediate behavior in that the monoanion absorption and ESR spectra are qualitatively similar to that of other olefinic $\mathrm{Mo}\left(\mathrm{dt}_{3}{ }_{3}^{-}\right.$spectra, but absorptivities, especially for the neutral compound, are much higher, and the main low-energy dianion peak is slightly blue-shifted from that of the neutral compound; moreover, a crystal structure shows an anion significantly twisted from ideal trigonal prismatic geometry $(\theta=$ $\left.18.0^{\circ}\right)[9]$

UV-vis.-NIR spectra were recorded for $\mathbf{1 b}$ and $\mathbf{1 c}$ and for the $\mathrm{NEt}_{4}{ }^{+}$salts of the corresponding dianions and monoanions, solutions of the latter being obtained through comproportionation of neutral and dianion species. As shown in Figure 5 and Table 4, the spectra of $\mathbf{1} \mathbf{b}^{n}$ and $\mathbf{1} \mathbf{c}^{n}$ for any given $n$ are rather similar to one another, those of the neutral species and monoanions also closely resembling those of $\mathbf{1 a}$ and $1 \mathbf{a}^{-}$, respectively $[23,31]$, while the low-energy maxima for the dianions are close to those reported for $\mathbf{1 a}^{2-}$ and $\mathbf{1} \mathbf{d}^{2-}[56,63]$. Furthermore spectra of $\mathbf{1 a}-\mathbf{c}^{n}$ are similar to those for $\operatorname{Mo}\left(\mathrm{S}_{2} \mathrm{C}_{2} \mathrm{RR}_{2}^{\prime}\right)_{3}{ }^{n}\left\{\mathrm{RR}^{\prime}=\mathrm{H}_{2}, \mathrm{PhH} ; n=0,-1,-2\right\}[5,9]$ and $\mathrm{Mo}\left(\mathrm{S}_{2} \mathrm{C}_{2}(\mathrm{CN})_{2}\right)_{3}{ }^{n}\{n=-1,-2\}$ $[9,76]$ species with the same value of $n$; the maxima for $\mathbf{1 a - c ^ { n }}$ are all slightly hypsochromically shifted relative to those of their $\mathrm{Mo}\left(\mathrm{S}_{2} \mathrm{C}_{2} \mathrm{H}_{2}\right)_{3}{ }^{n}$ analogues (ca. 170-670 $\mathrm{cm}^{-1}$ shift for the strong maxima in the 500-700 $\mathrm{nm}$ range). This suggests that, despite the presence of strongly electron-withdrawing substituents, the electronic and geometric structures of these species, and in particular of the monoanions, are similar to those of the 
prototypical $\mathrm{S}_{2} \mathrm{C}_{2} \mathrm{H}_{2}$ olefinic dt ligand. This is consistent with the previously reported crystal structure of a $1 \mathbf{a}^{-}$salt [26], which shows a near-ideal trigonal prismatic geometry, as well as with DFT calculations, which also indicate a trigonal prismatic geometry and a ligand-based SOMO [41].
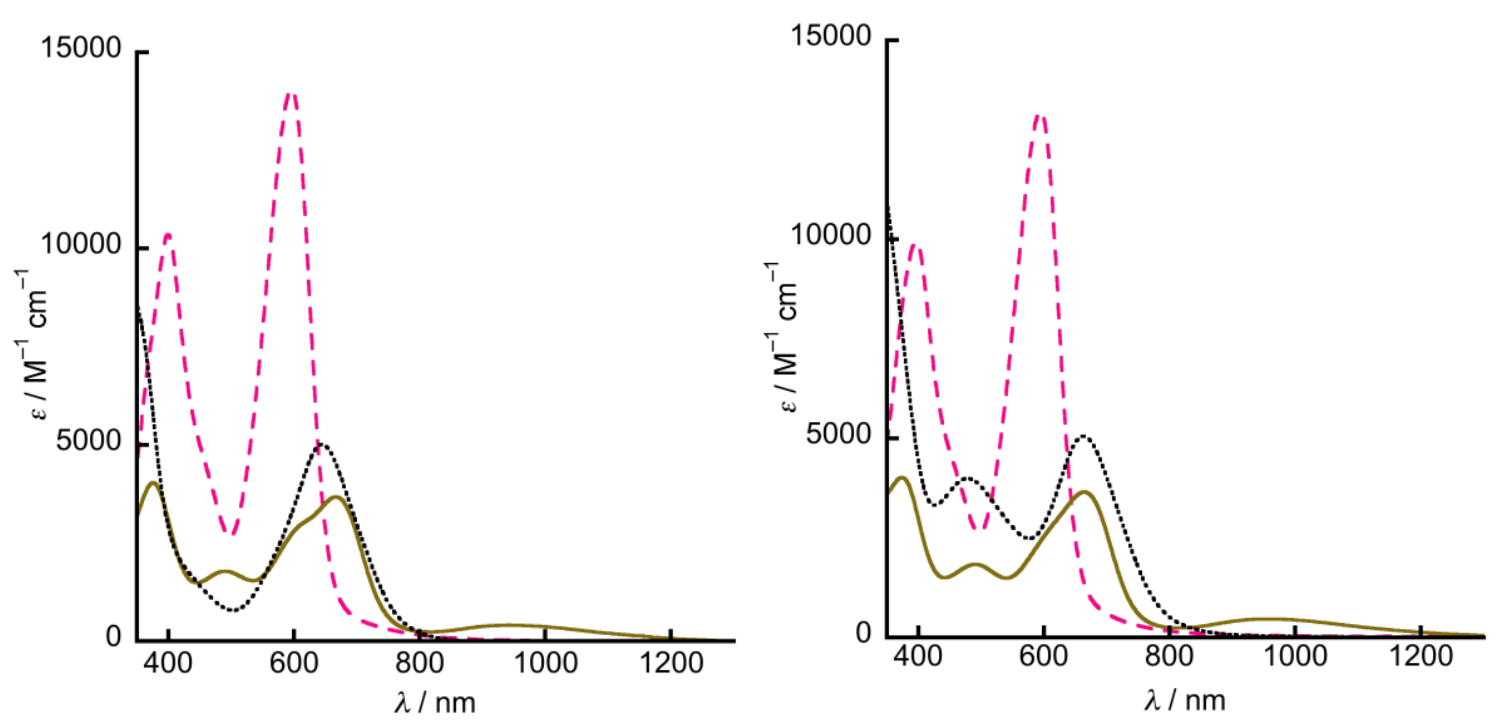

Figure 5. Electronic absorption spectra in $\mathrm{CH}_{2} \mathrm{Cl}_{2}$ for $\mathbf{1 b}$ (left) and $\mathbf{1 c}$ (right) in neutral (broken lines), monoanionic (solid lines), and dianionic (dotted lines) oxidation states. 


\section{Conclusions}

Molybdenum tris[1-(methoxycarbonyl)-2-(trifluoromethyl)-ethane-1,2-dithiolene], 1b, and molybdenum tris[1-(trifluoroethanoyl)-2-(trifluoromethyl)ethane-1,2-dithiolene], 1c, have been synthesized as more soluble p-dopants than $\mathrm{Mo}(\mathrm{tfd})_{3}$, 1a. Compounds $\mathbf{1 b}$ and 1c are, respectively, less and more strongly oxidizing than $\mathbf{1 a}$; $\mathbf{1 c}$ being the most strong oxidizing $\operatorname{Mo}(\mathrm{dt})_{3}$ derivative to have been isolated in the neutral state, while the weakly oxidizing behavior of $\mathbf{1 b}$ suggests that the $\pi$-acceptor properties of the carbonyl-based substituents do not play a major role in stabilizing the anions. The electronic spectra of the complexes are similar to those of other $\mathrm{Mo}(\mathrm{dt})_{3}$ complexes in the same oxidation states that lack aryl substitution or fused arene rings.

\section{Acknowledgments}

We thank the ONR (N00014-11-1-0313 and N00014-14-1-0126) and the NSF (PREM DMR-0934212 and DMR-1523611) for support. We also thank a reviewer for helpful comments.

\section{Appendix A. Supplementary data}

CCDC 1449813-5 contain the supplementary crystallographic data. These data can be obtained free of charge via http://www.ccdc.cam.ac.uk/conts/retrieving.html, or from the Cambridge Crystallographic Data Centre, 12 Union Road, Cambridge CB2 1EZ, UK; fax: (+44) 1223-336-033; or e-mail: deposit@ccdc.cam.ac.uk. 


\section{References}

[1] M.L.H. Green, J. Organomet. Chem., 500 (1995) 127.

[2] A. Davison, N. Edelstein, R.H. Holm, A.H. Maki, J. Am. Chem. Soc., 86 (1964) 2799.

[3] A.E. Smith, G.N. Schrauzer, V.P. Mayweg, W. Heinrich, J. Am. Chem. Soc., 87 (1965) 5798.

[4] E.I. Stiefel, R. Eisenberg, R.C. Rosenberg, H.B. Gray, J. Am. Chem. Soc., 88 (1966) 2956.

[5] G.N. Schrauzer, V.P. Mayweg, J. Am. Chem. Soc., 88 (1966) 3235.

[6] D.C. Olson, V.P. Mayweg, G.N. Schrauze, J. Am. Chem. Soc., 88 (1966) 4876.

[7] R.R. Kapre, E. Bothe, T. Weyhermüller, S.D. George, K. Wieghardt, Inorg. Chem., 46 (2007) 5642.

[8] A.L. Tenderholt, R.K. Szilagyi, R.H. Holm, K.O. Hodgson, B. Hedman, E.I. Solomon, Inorg. Chem., 47 (2008) 6382.

[9] S. Sproules, P. Banerjee, T. Weyhermuller, Y. Yan, J.P. Donahue, K. Wieghardt, Inorg. Chem., 50 (2011) 7106.

[10] R. Eisenberg, Coord. Chem. Rev., 255 (2011) 825.

[11] U. Fekl, B. Sarkar, W. Kaim, M. Zimmer-De Iuliis, N. Nguyen, Inorg. Chem., 50 (2011) 8685 .

[12] S. Sproules, Prog. Inorg. Chem., 58 (2014) 1.

[13] I.K. Dhawan, A. Pacheco, J.H. Enemark, J. Am. Chem. Soc., 116 (1994) 7911.

[14] B.S. Lim, J.P. Donahue, R.H. Holm, Inorg. Chem., 39 (2000) 263.

[15] D.V. Fomitchev, B.S. Lim, R.H. Holm, Inorg. Chem., 40 (2001) 645. 
[16] B.L. Westcott, N.E. Gruhn, J.H. Enemark, J. Am. Chem. Soc., 120 (1998) 3382.

[17] R.H. Holm, E.I. Solomon, A. Majumdar, A. Tenderholt, Coord. Chem. Rev., 255 (2011) 993.

[18] N. Nguyen, A.J. Lough, U. Fekl, Inorg. Chem., 51 (2012) 6446.

[19] B.R. Williams, Y. Fu, G.P.A. Yap, S.J. Nieter Burgmayer, J. Am. Chem. Soc., 134 (2012) 19584.

[20] H. Sugimoto, S. Tatemoto, K. Toyota, K. Ashikari, M. Kubo, T. Ogura, S. Itoh, Chem. Commun., 49 (2013) 4358.

[21] Y. Ha, A.L. Tenderholt, R.H. Holm, B. Hedman, K.O. Hodgson, E.I. Solomon, J. Am. Chem. Soc., 136 (2014) 9094.

[22] R. Hille, Chem. Rev., 96 (1996) 2757.

[23] R.B. King, S. Ikai, J. Mol. Catal., 4 (1978) 361.

[24] D.J. Harrison, A.J. Lough, N. Nguyen, U. Fekl, Angew. Chem. Int. Ed., 46 (2007) 7644.

[25] M.L.H. Green, A. Hamnett, J. Qin, P. Baird, J.A. Bandy, K. Prout, E. Marseglia, S.D. Obertelli, J. Chem Soc., Chem. Commun., (1987) 1811.

[26] W.B. Heuer, P. Mountford, M.L.H. Green, Simon G. Bott, D. O'Hare, J.S. Miller, Chem. Mater., 2 (1990) 764.

[27] P. Baird, J.A. Bandy, M.L.H. Green, A. Hamnett, E. Marseglia, D.S. Obertelli, K. Prout, J. Qin, J. Chem. Soc., Dalton Trans. Faraday Soc., (1991) 2377.

[28] G. Matsubayashi, K. Douki, H. Tamura, M. Nakano, Inorg. Chem. , 32 (1993) 5990. 
[29] L. Qu, N.S. Makarov, C. Zhong, J.W. Perry, J. Qin, J. Mater. Chem. C, 2 (2014) 614.

[30] K. Walzer, B. Maenning, M. Pfeiffer, K. Leo, Chem. Rev., 107 (2007) 1233.

[31] Y. Qi, T. Sajoto, S. Barlow, E.-G. Kim, J.-L. Brédas, S.R. Marder, A. Kahn, J. Am. Chem. Soc., 131 (2009) 12530.

[32] W. Gao, A. Kahn, Appl. Phys. Lett., 79 (2001) 4040.

[33] J. Li, G. Zhang, D.M. Holm, I.E. Jacobs, B. Yin, P. Stroeve, M. Mascal, A.J. Moule, Chem. Mater., 27 (2015) 5765.

[34] I. Bruder, S. Watanabe, J. Qu, I.B. Mueller, R. Kopecek, J. Hwang, J. Weis, N. Langer, Org. Electron., 11 (2010) 589.

[35] P.K. Koech, A.B. Padmaperuma, L. Wang, J.S. Swensen, E. Polikarpov, J.T. Darsell, J.E. Rainbolt, D.J. Gaspar, Chem. Mater., 22 (2010) 3926.

[36] P. Tyagi, M.K. Dalai, C.K. Suman, S. Tuli, R. Srivastava, RSC Adv., 3 (2013)) 24553.

[37] J. Li, C.W. Rochester, I.E. Jacobs, S. Friedrich, P. Stroeve, M. Riede, A.J. Moule, ACS Appl. Mater. Interf., 7 (2015) 28420.

[38] I. Salzmann, G. Heimel, S. Duhm, M. Oehzelt, P. Pingel, B.M. George, A. Schnegg, K. Lips, Ralf-Peter Blum, A. Vollmer, N. Koch, Phys. Rev. Lett., 108 (2012) 035502.

[39] F. Ghani, A. Opitz, P. Pingel, G. Heimel, I. Salzmann, J. Frisch, D. Neher, A. Tsami, U. Scherf, N. Koch, J. Poly. Sci. Part B: Poly. Phys., 53 (2015) 58.

[40] For some organic p-dopants that have been developed to address some of these drawbacks of $\mathrm{F}_{4}-\mathrm{TCNQ}$, see, for example, refs [34], [35], and [37]. 
[41] Y. Qi, T. Sajoto, M. Kröger, A.M. Kandabarow, W. Park, S. Barlow, E.-G. Kim, L. Wielunski, L.C. Feldman, R.A. Bartynski, J.-L. Brédas, S.R. Marder, A. Kahn, Chem. Mater., 22 (2010) 524.

[42] S.P. Tiwari, W.J. Potscavage, T. Sajoto, S. Barlow, S.R. Marder, B. Kippelen, Org. Electron., 11 (2010) 860.

[43] W. Zhao, Y. Qi, T. Sajoto, S. Barlow, S.R. Marder, A. Kahn, Appl. Phys. Lett., 97 (2010) 123305.

[44] O. Zeika, A. Werner, H. Hartmann, S. Willmann, PCT Int. Appl. WO 2008/061517, (2008).

[45] J.-H. Lee, H.-M. Kim, K.-B. Kim, R. Kabe, P. Anzenbacher, J.-J. Kim, Appl. Phys. Lett., 98 (2011) 173303.

[46] G. Heimel, I. Salzmann, N. Koch, AIP Conf. Proc., 1456 (2012) 148.

[47] S.A. Paniagua, J. Baltazar, H. Sojoudi, S.K. Mohapatra, S. Zhang, C.L. Henderson, S. Graham, S. Barlow, S.R. Marder, Mater. Horiz., 1 (2014) 111.

[48] A. Dai, Y. Zhou, A.L. Shu, S.K. Mohapatra, H. Wang, C. Fuentes-Hernandez, Y. Zhang, S. Barlow, Y.-L. Loo, S.R. Marder, B. Kippelen, A. Kahn, Adv. Funct. Mater., 24 (2014) 2197.

[49] J. Belasco, S.K. Mohapatra, Y. Zhang, S. Barlow, S.R. Marder, A. Kahn, Appl. Phys. Lett., 105 (2014) 063301/1.

[50] A. Dai, A. Wan, C. Magee, Y. Zhang, S. Barlow, S.R. Marder, A. Kahn, Org. Electron., 23 (2015) 151.

[51] A. Davison, R.H. Holm, R.E. Benson, M. Mahler, Inorg. Synth., 10 (1967) 8. [52] S. Barlow, Inorg. Chem., 40 (2001) 7047. 
[53] $\mathrm{FeCp}_{2}$ itself was not used as a reference since its oxidation overlaps with the reduction of some of the $\mathrm{Mo}(\mathrm{dt})_{3}$ compounds examined here.

[54] M. Draganjac, E. Simhon, L.T. Chan, M. Kanatzidis, N.C. Baenziger, D. Coucouvanis, Inorg. Chem., 21 (1982) 3321.

[55] R.B. King, Inorg. Chem., 2 (1963) 641.

[56] K. Wang, J.M. McConnachie, E.I. Stiefel, Inorg. Chem., 38 (1999) 4334.

[57] C.G. Krespan, J. Am. Chem. Soc., 83 (1961) 3434.

[58] O. Jeannin, M. Fourmigué, Chem. Eur. J., 12 (2006) 2994.

[59] Q. Chong, X. Xin, C. Wang, F. Wu, H. Wang, J.-C. Shi, B. Wan, J. Org. Chem., 79 (2014) 2105.

[60] J. Chen, G.-Q. Lin, Z.-M. Wang, H.-Q. Liu, Synlett., (2002) 1265.

[61] Y. Shen, W. Qiu, Y. Xin, Y. Huang, Synthesis, 11 (1984) 924.

[62] It is worth noting that alternative approaches to dithetenes are available, but were not pursued in the present work. For example, a low-yielding preparation of the dithetene that corresponds to the alkyne Id has been reported in which a bis(cyclopentadienyl)titanium dithiolene intermediate, which itself is obtained from $\mathrm{TiCp}_{2} \mathrm{~S}_{5}$ and the alkyne, is treated with $\mathrm{SO}_{2} \mathrm{Cl}_{2}$. See: (a) C.M. Bolinger, T.B. Rauchfuss, Inorg. Chem. 21 (1982) 3947; (b) T. Shimizu, H. Murakami, Y. Kobayashi, K. Iwata, N. Kamigata, J. Org. Chem. 63 (1998) 8192).

[63] M. Draganjac, D. Coucouvanis, J. Am. Chem. Soc., 105 (1983) 139.

[64] J.K. Kochi, Acc. Chem. Res., 25 (1992) 39.

[65] D. Argyropoulos, C.-A. Mitsopoulou, D. Katakis, Inorg. Chem., 35 (1996) 5549. 
[66] D. Argyropoulos, E. Lyris, C.A. Mitsopoulou, D. Katakis, J. Chem. Soc., Dalton Trans., (1997) 615.

[67] Dissolution of $\mathbf{1} \mathbf{c}$ in $\mathrm{MeCN}$ or $\mathrm{Me}_{2} \mathrm{CO}$ results in immediate formation of $\mathbf{1 c}^{-}$, as revealed by UV-vis.-NIR spectroscopy, while the complete reduction in THF takes several hours. No such behavior is seen in $\mathrm{CH}_{2} \mathrm{Cl}_{2}$. Moreover, even when additional water is added to $\mathrm{CH}_{2} \mathrm{Cl}_{2}$ solutions and the mixture is vigorously stirred, $\mathbf{1} \mathbf{c}^{-}$is not observed; instead there is a slow loss of $\mathbf{1 c}$ absorptions and no growth of new strong visible or NIR absorptions, presumably indicating decomposition of the $\mathrm{M}(\mathrm{dt})_{3}$ core.

[68] A. Cervilla, F. Pérez-Plá, E. Llopis, M.a. Piles, J. Chem Soc., Dalton Trans., (2004) 1461.

[69] H. Sugimoto, Y. Furukawa, M. Tarumizu, H. Miyake, K. Tanaka, H. Tsukube, Eur. J. Inorg. Chem., (2005) 3088.

[70] D. Formitchev, B.S. Lim, R.H. Holm, Inorg. Chem., 40 (2001) 645.

[71] H.-W. Xu, Z.-N. Chen, J.-G. Wu, Acta Crystallogr., E58 (2002) m631.

[72] G.F. Brown, E.I. Stiefel, Inorg. Chem., 12 (1973) 2140.

[73] S. Campbell, S. Harris, Inorg. Chem., 35 (1996) 3285.

[74] S. Friedle, D.V. Partyka, M.V. Bennett, R.H. Holm, Inorg. Chim. Acta, 359 (2006) 1427.

[75] M. Cowie, M.J. Bennett, Inorg. Chem., 15 (1976) 1584.

[76] E.I. Stiefel, L.E. Bennett, Z. Dori, T.H. Crawford, C. Simo, H.B. Gray, Inorg. Chem., 9 (1970) 281. 
[77] Two definitions of EA are in widespread use and differ in the sign obtained for a given material; here we define EA as the energy released (rather than absorbed) on capture of an electron from the vacuum level.

[78] Although, strictly speaking it is the EA of the dopant in a matrix of the host that is relevant, it is the EA of the dopant in a neat film that is generally measured by IPES; these values will be similar if the dielectric constants of the two solids are similar.

[79] $\mathrm{EA}(\mathrm{s})$ are often estimated from solution reduction potentials using relations of the form $\mathrm{EA}=a+b e E_{\text {red }}$ where $a$ and $b$ are constants, often with $b=1$, and $e$ is the electronic charge. Such relations implicitly assume either (when $b=1$ ) that the difference between solvation effects and solid-state polarization effects is the same for all molecules, or (when $b \neq 1$ ) that this difference is a function of reduction potential; neither of these assumptions seems very reasonable given that one would expect solvation and polarization energies to depend on molecular size, shape, and charge distribution.

[80] C. Hansch, A. Leo, R.W. Taft, Chem. Rev., 91 (1991) 165.

[81] This picture is qualitatively consistent with the reductions involving the ligands loosing neutral, di(thioketone), character and gaining dianionic, di(dithiolate), character (as suggested by the structural data discussed in the text and by DFT orbital calculations for olefinic $\mathrm{Mo}(\mathrm{dt})_{3}{ }^{-}$species in refs [8], [9], and [41]) . In a neutral thioketone ligand, a resonance structure can be drawn in which the $\mathrm{C}(\mathrm{S})$ (to which the substituent is attached) bears a positive charge, whereas comparable structures cannot be drawn for a thiolate ligand. 
[82] C. Schulze Isfort, T. Pape, F.E. Hahn, Eur. J. Inorg. Chem., (2005) 2607.

[83] S. Boyde, C.D. Garner, J.H. Enemark, M.A. Bruck, J.G. Kristofzski, J. Chem. Soc., Dalton Trans. Faraday Soc., (1987) 2267. 


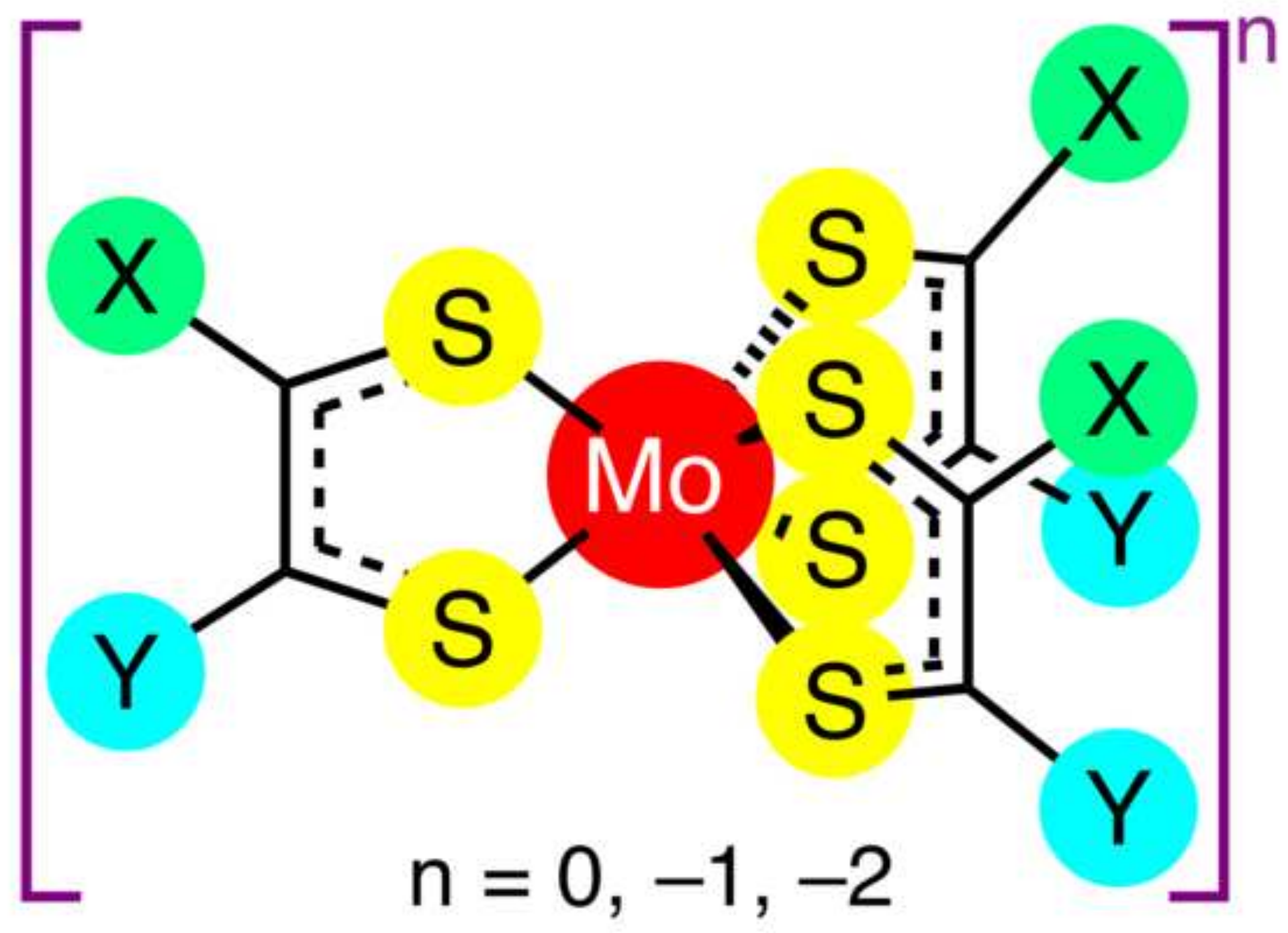

$\mathrm{X}=\mathrm{CF}_{3}, \mathrm{Y}=\mathrm{CO}_{2} \mathrm{Me}$ vs. $\mathrm{X}=\mathrm{Y}=\mathrm{CF}_{3}$ $\mathrm{X}=\mathrm{CF}_{3}, \mathrm{Y}=\mathrm{COCF}_{3} \mathrm{X}=\mathrm{Y}=\mathrm{CO}_{2} \mathrm{Me}$ 
The reaction of $\mathrm{MoS}_{9}{ }^{2-}$ with alkynes $\mathrm{CF}_{3} \mathrm{CCCO}_{2} \mathrm{Me}$ and $\mathrm{CF}_{3} \mathrm{CCCOCF}_{3}$ to gives dianions of the corresponding tris(dithiolene) complexes, which can be oxidized to their neutral analogues using $\mathrm{NOPF}_{6}$. The complexes have been characterized in various oxidation states by crystallography, electrochemistry, and UV-vis-spectroscopy, and compared to $\mathrm{Mo}\left(\mathrm{S}_{2} \mathrm{C}_{2}\left(\mathrm{CF}_{3}\right)_{2}\right)_{2}{ }^{\mathrm{n}}$ and $\mathrm{Mo}\left(\mathrm{S}_{2} \mathrm{C}_{2}\left(\mathrm{CO}_{2} \mathrm{Me}\right)_{2}\right)_{2}{ }^{\mathrm{n}}$. 